\title{
ESTUDO COMPARATIVO ENTRE A ABORDAGEM DE TRANSITIVIDADE VERBAL E OBJETO DIRETO NA GRAMÁTICA NORMATIVA DE ROCHA LIMA E NA GRAMÁTICA DESCRITIVA DE MOURA NEVES
}

Bárbara Cazumbá (UERJ)

Resumo: Este trabalho analisa as abordagens da transitividade verbal e do objeto direto realizadas na Gramática Normativa da Língua Portuguesa de Rocha Lima (2011) e na Gramática de usos do português de Moura Neves (2011). O principal objetivo é demonstrar como as duas perspectivas de análise linguística - normativa e descritiva - são relevantes para o ensino de língua, a partir do momento em que dão bases para que alunos e professores possam refletir sobre a gramática do idioma. Inicialmente, faz-se uma revisão acerca da história das teorias linguísticas, demonstrando as características fundamentais de análise de cada uma e já apontando as diferenças entre uma teoria formalista e uma teoria funcionalista. Após, apresentam-se as estruturas das gramáticas a serem estudadas para, enfim, observar como cada uma apresenta a noção de transitividade verbal e de objeto direto. Por fim, reflete-se sobre o ensino de língua nas escolas e como cada gramática pode se relacionar com esse ensino.

Palavras-chave: Gramática normativa; Gramática descritiva; Ensino.

Abstract: This work analyzes the approaches of verbal transitivity and direct object made in the Gramática Normativa da Língua Portuguesa of Rocha Lima (2011) and in the Gramática de usos do português by Moura Neves (2011). The main objective is to demonstrate how the two perspectives of linguistic analysis - normative and descriptive - are relevant to the teaching of language, from the moment they provide the basis for students and teachers to reflect on the grammar of the language. Initially, a review is made about the history of linguistic theories, demonstrating the fundamental characteristics of analysis of each one and already pointing out the differences between a formalist theory and a functionalist theory. Afterwards, the structures of the grammars to be studied are presented, in short, to observe how each one presents the notion of verbal transitivity and direct object. Finally, 
it reflects on language teaching in schools and how each grammar can relate to that teaching.

Keywords: Normative grammar; Descriptive grammar; Teaching.

\section{INTRODUÇÃO}

Meu objetivo com esse artigo não é discutir mais uma vez a utilidade ou inutilidade do ensino de gramática nas salas de aulas brasileiras, já que tal discussão travada nas últimas décadas não ampliou a capacidade dos discentes em interpretar e relacionar as informações presentes em diversos textos ou identificar os elementos gramaticais da língua, conforme foi constatado no Saeb $2017^{1}$. O fato é: enquanto refletimos nas academias qual nomenclatura adotar ou se iremos rasgar de vez as gramáticas tradicionais, alunos não conseguem obter o desempenho mínimo esperado ao saírem do Ensino Médio.

De acordo com Perini (2010, p.17), a gramática deve ser observada como uma disciplina científica, isto é, existem diferentes métodos de análises para estudar aspectos da linguagem. Assim, há diversas formas de se entender um mesmo elemento linguístico e esse deve ser o foco do ensino de língua. A escola servirá, então, como uma porta que abre o caminho para a instigação científica do aluno. Este, por sua

1 A pesquisa aponta que, em Português, 70,88\% dos alunos do Ensino Médio têm nível insuficiente de aprendizado. 
vez, terá a possibilidade de questionar teorias e trazer novas formas de análise.

Por outro lado, como esperar que alunos tenham espaços para reflexão se, ao final do 3 ano do Ensino Médio, há um vestibular esperando-os, com uma proposta de redação que aguarda o conhecimento deles acerca do uso da norma padrão da língua, uma norma estruturada a partir do uso de língua de obras de grandes escritores? É preciso, então, que antes de abrir espaço para a reflexão, seja feito um trabalho para que esses alunos tenham acesso à variedade da língua portuguesa que é aceita em espaços tidos como "pertencentes à elite" e, caso a escola não dê esse acesso à norma padrão, o colégio torna-se opressor "na medida em que não se dá ao falante a liberdade de escolher, para cada ocasião de intercâmbio social, a modalidade que melhor sirva à mensagem, ao seu discurso" (BECHARA, 2007, p.14). O aluno deve ser um poliglota em sua própria língua. Negar o conhecimento dessa variedade aos discentes é reforçar o estigma já existente contra alunos oriundos das classes mais pobres.

Isso posto, pretendo com esse trabalho demonstrar a diferença entre a análise sintática proposta pela Gramática Normativa da Língua Portuguesa de Rocha Lima e a análise sintática proposta pela Gramática de usos do português de 
Maria Helena de Moura Neves, reforçando a importância dos dois modelos de gramática (normativa e descritiva) no ensino gramatical. Dentre os aspectos sintáticos, será focalizado o tratamento dado pelos gramáticos à relação entre o verbo e o complemento verbal não preposicionado (objeto direto), pois é a partir desse ponto que ocorre o ensino de vozes verbais nas escolas e inicia-se o conteúdo de transitividade verbal. Antes de apresentar a diferença de abordagem proposta nessas gramáticas para o mesmo elemento gramatical, trago na próxima seção o contraste entre formalismo e funcionalismo, já que as gramáticas a serem analisadas possuem perspectivas de estudo linguístico diferentes: uma é formalista e a outra, funcionalista.

\section{ASPECTOS DO FORMALISMO E DO FUNCIONALISMO NA ABORDAGEM GRAMATICAL}

Conforme já indica a nomenclatura, o formalismo compreende a língua a partir de sua estrutura, sua forma. Assim, "a língua é um conjunto de orações, cujo correlato psicológico é a competência" (CASTILHO, 2002, p.19), isto é, a estrutura utilizada nas orações representa a capacidade cognitiva do falante. A língua aparece como um sistema autônomo que deve ser observado a partir da sua própria estrutura, focando a fonética, fonologia, morfologia e sintaxe. 
A publicação do Curso de Linguística Geral em 1916 traz a visão estruturalista da língua, rompendo com a tradição histórica dos estudos de linguagem. Pelo pensamento de Saussure, o signo linguístico aparece como unidade a ser estudada a partir do método comparativo das formas. Esse signo linguístico é dividido em duas partes: o significante, que é a imagem sonora do signo, e o significado, que é a imagem mental relacionada ao signo. A relação entre esses dois elementos do signo linguístico é arbitrária, não motivada. Não há, pois, uma relação entre a forma e o conteúdo.

Ao estabelecer o signo como unidade de análise da Linguística, Saussure aponta que o foco do estudo da linguagem deve ser a langue (a língua em si, fundamentada e estruturada no campo social) e não a parole (situada na esfera individual). Segundo Chiavegatto (2009), foi com o estruturalismo saussuriano que a Linguística recebeu o estatuto científico de que hoje desfruta, pois se passou a descrever maciçamente a língua por quase todo o século XX.

Na década de 1930, verificamos nos Estados Unidos o trabalho desenvolvido por Bloomfield. As ideias trazidas pelo linguista relacionavam os princípios behavioristas à língua, observando e descrevendo como os estímulos externos levam uma pessoa a falar - princípio de estímulo e resposta. 
É uma teoria de análise comportamental. O indivíduo é considerado uma tábula-rasa e, a partir de influências externas (ambiente), ele absorve as regras da língua. 0 trabalho do linguista deve ser, então, o de analisar a língua na busca de um comportamento comum que rege o sistema da língua.

Bloomfield deixa importante contribuição para o estudo das construções das palavras. Ele designa morfema as unidades mínimas da língua que possuem significado e apresenta três formas de construção morfológica das palavras: composição (palavras formadas por duas formas livres, i.e, formas que possuem significação ao serem enunciadas, sem depender de outra forma), derivação secundária (palavras formadas pela derivação de uma forma base) e derivação primária (palavras que contêm mais de uma forma ligadas) (NASCIMENTO, 2014, p.37).

Em 1960 surge o gerativismo. Essa teoria aparece como resposta aos estudos de Bloomfield, rejeitando a perspectiva de a aprendizagem da linguagem estar condicionada a estímulos e respostas motivados socialmente. Chomsky acredita que a criatividade ao se construir sentenças é o que diferencia justamente a linguagem humana da comunicação dos outros animais, o que não seria possível se a linguagem fosse baseada somente em repetições condicionadas. 
O gerativismo vai se preocupar com a sintaxe das línguas como forma de encontrar propriedades comuns a todas elas, chegando-se à Gramática Universal (GU). Uma hipótese que sustentaria a existência dessa GU seria a aquisição da linguagem pelas crianças. Não é somente o convívio em sociedade que faria com que a criança aprendesse todas as regras de uma língua, mas, na verdade, esse convívio despertaria um sistema interno do indivíduo que seria responsável pela aquisição. Para Chomsky,

a aquisição da linguagem é homogênea, isto é, independe de classe social, grau de estimulação e tem lugar entre 1 e 4 anos; a aquisição também é completa, ou seja, a criança aprende todo o sistema lingüístico. Não há casos de aprendizagem parcial: seria uma hipótese absurda a criança aprender as frases interrogativas, mas não saber estruturar nem interpretar as frases relativas porque a mãe trabalha fora e não tem tempo de ensinar. (VITRAL, 1996, p.71)

A língua é, então, um sistema de representação mental, e o falante ativa esse sistema de duas formas: a partir da competência e do desempenho. Para Chomsky, "competência é o conhecimento potencial internalizado que o indivíduo possui da língua e que o permitirá avaliar as sentenças produzidas, e a performance diz respeito ao uso efetivo da língua em situações concretas de uso" (CORTEZ, 2011, p.63). 
A competência é a face criativa da língua, que permite ao falante produzir diversos enunciados e a habilidade em se utilizar a língua refere-se ao desempenho.

Todas as teorias formalistas primam pela análise sintática sobre a pragmática, ainda que apontem que a língua ocorre em situações interativas: a língua como mecanismo de comunicação é percebida quando Saussure aborda a parole, quando Bloomfield verifica os estímulos externos sobre a fala e quando Chomsky aponta para o princípio do desempenho.

Já o funcionalismo, que ganha notoriedade a partir dos anos 1970, verifica a língua como mecanismo de interação social. A estrutura linguística é motivada pela situação social em que a troca comunicativa ocorre. Portanto, uma pesquisa funcionalista "concentra-se no esclarecimento das relações entre forma e função, especificando aquelas funções que parecem exercer influência na estrutura gramatical" (CASTILHO, 2002, p.21).

Há diferentes teorias que são construídas a partir da perspectiva funcionalista da linguagem, mas todas compreendem a língua como uma competência comunicativa, isto é, os falantes possuem a capacidade de serem produtivos ao criarem diferentes sentenças em diferentes situações. Assim, a sintaxe da língua é maleável ao uso e, por isso, não é totalmente arbitrária. 
Uma das subteorias funcionalistas é a Linguística Sistêmico-Funcional. De acordo com essa perspectiva, a seleção vocabular e a sintaxe são organizadas pelo contexto. É o paradigma que estipula a organização da sentença. Segundo Halliday (2002), a linguagem modifica a intenção comunicativa e deixa-se modificar por ela, ou seja, a língua se estrutura a partir dos diversos usos em diferentes situações sociais, mas também determina as relações expressas nessas situações. Dessa forma, uma sentença é também um modo de reflexão, de ordenar as variáveis de um evento.

A Linguística Sistêmico-Funcional é sistêmica porque observa a língua pelo viés semântico norteador das escolhas no eixo dos paradigmas; e é funcional porque "explica as estruturas gramaticais em relação ao significado, às funções que a linguagem desempenha em textos" (FUZER; CABRAL, 2014, p.9), em que essa função nos textos só pode ser remontada ao verificar o contexto da interação.

Para toda enunciação dada em um determinado contexto específico, são necessárias funções desempenhadas pela linguagem que norteie a efetividade da comunicação: uma que identifique a realidade a ser transmitida pelo enunciador, outra que estabeleça as relações entre os participantes da comunicação e uma terceira que estruture o enunciado, 
permitindo que haja a compreensão entre os interlocutores. Permeiam, então, três metafunções em toda estrutura linguística: a ideacional, em que o indivíduo representa a sua percepção de mundo; a interpessoal, que demonstra a intenção comunicativa durante a troca de mensagens entre o locutor e o interlocutor; e a textual, que se configura na parte superficial da mensagem.

Partindo da perspectiva social da língua, deparamo-nos também com a Sociolinguística. Essa teoria observa que a língua é uma forma de ação social, preenchendo propósitos culturais e sociais. Assim como a Sistêmico-Funcional, essa teoria parte também da ideia de que a sintaxe está ancorada à pragmática.

William Labov assina uma das ramificações da Sociolinguística: a Sociolinguística Variacional. Ele observa que a fala de uma comunidade linguística é heterogênea, pois não há dois falantes de uma mesma comunidade que se expressem da mesma forma em variados contextos de comunicação. A língua é, portanto, um sistema heterogêneo, diferentemente do que propunham Saussure e Chomsky. Entretanto, essa heterogeneidade é organizada:

Então, mesmo que a princípio se possa pensar que heterogeneidade implica ausência de regras, a língua é dotada de heterogeneidade estruturada, portanto há regras, sim. Só 
que, enquanto a língua concebida como sistema homogêneo contém somente regras categóricas, ou obrigatórias, ou invariantes (i.e., que sempre se aplicam da mesma maneira por todos) a língua concebida como um sistema heterogêneo comporta, ao lado de regras categóricas, também regras variáveis.

(GÖRSKI et al., 2010, p.24, grifo do autor)

Assim, a Sociolinguística Variacionista analisa em quais situações comunicativas as regras da língua tendem a mudar e em quais situações as regras permanecem fixas. Sua preocupação é entender como o meio social do indivíduo influencia na estrutura da língua.

A outra corrente da Sociolinguística, a Interacional, interessa-se pela interação face a face e as estratégias utilizadas pelo indivíduo a depender do receptor da mensagem. A interação é o ponto de partida para a análise linguística e os interlocutores são co-construtores ativos da comunicação, pois juntos formam os sentidos dos encontros sociais.

Ao longo da troca comunicativa, os interlocutores deixam pistas que serão interpretadas para que haja fluidez na comunicação. Essas pistas são "qualquer característica de forma linguística que contribui para a sinalização de pressuposições contextuais" (GUMPERZ, 1982, p.131). Dessa forma, não só a língua traz significados, mas também a prosódia e o posicionamento corporal, por exemplo. 
De forma geral, uma gramática formalista irá analisar as características internas da língua, com ênfase em uma sintaxe autônoma, sem relacionar a estrutura linguística ao contexto. As regras da língua são, portanto, rígidas. Já uma gramática funcionalista relacionará a estrutura da língua ao contexto. Enquanto a primeira explica a língua por ela mesma, a segunda observa os componentes discursivos atrelados à língua.

Apresentadas as diferenças entre o formalismo e o funcionalismo, na próxima seção veremos como uma gramática tradicional formalista estuda as relações do verbo dentro da oração e como uma gramática descritiva funcionalista observa esse mesmo elemento gramatical.

\section{DIFERENÇAS GERAIS ENTRE AS GRAMÁTICAS}

No prefácio e na apresentação das gramáticas a serem analisadas, já verificamos a diferente perspectiva entre os dois livros:

a) Gramática Normativa da Língua Portuguesa:

Nada mais que isso, para que a GN continue a ser, fundamentalmente, o que sempre aspirou a ser: um livro redigido com simplicidade e clareza, e norteado por obsessiva busca de exatidão no sistematizar as normas da modalidade culta do idioma nacional - dever primeiro do ofício do professor de português.

(ROCHA LIMA, 2011, s/p.) 
b) Gramática de usos do português

A Gramática de usos do português constitui uma obra de referência que mostra como está sendo usada a língua portuguesa atualmente no Brasil. Para isso, ela parte dos próprios itens lexicais e gramaticais da língua e, explicitando o seu uso em textos reais, vai compondo as "gramáticas" desses itens, isto é, vai mostrando as regras que regem o seu funcionamento e, todos os níveis, desde o sintagma até o texto. A meta final, no exame, é buscar os resultados de sentido, partindo do princípio de que é no uso que diferentes itens assumem seu significado e definem sua função, e de que as entidades da língua têm de ser avaliadas em conformidade com o nível em que ocorrem, definindo-se, afinal, na sua relação com o texto.

(MOURA NEVES, 2011, p.13)

Percebe-se que a gramática de Rocha Lima é normativa e, apesar de constatar a existência da variedade da língua, propõe a análise linguística com base na norma culta, que, para ele, deve ser a norma de ensino nas aulas de português. Já a gramática de Moura Neves é descritiva e propõe a análise de língua a partir dos usos cotidianos dos falantes no Brasil.

A organização dos sumários também apresenta a diferença na forma de se analisar a língua por essas gramáticas. Na Gramática Normativa da Língua Portuguesa encontramos a sequência tradicional que parte do estudo da Fonética e Fonologia da língua, com a tonicidade, separação silábica, 
acentuação e ortografia, passa pela Morfologia com os estudos das classes gramaticais e formação de palavras, vai para a Sintaxe, com o estudo analítico dos enunciados e suas construções, e chega à Estilística. Observa-se, com essa divisão, a visão fragmentada da análise linguística, em que a estrutura não se relaciona com a Pragmática no estudo de língua. Dessa forma, a Estilística aparece somente ao final da gramática, após o estudante percorrer por todos os outros aspectos da língua.

O sumário da Gramática de usos do português começa com o estudo da sentença a partir de uma perspectiva funcionalista. São apresentadas a noção de verbo para abordar predicação, a noção de substantivo e adjetivo para abordar os argumentos exigidos pelo verbo e as circunstâncias expressas pelos advérbios, que podem desempenhar função satélite. A segunda parte dedica-se ao estudo da referenciação situacional e textual, onde se abordam os artigos e os pronomes. Após, demonstram-se os pronomes e artigos indefinidos e os numerais, ou seja, os processos de indefinição e quantificação. A última parte versa sobre as formas de se ligarem as palavras e orações, relacionando as preposições e conjunções à Semântica. Vêse que o princípio de organização da gramática parte do enunciado para a obtenção do sentido do texto. 
A noção da predicação verbal e dos complementos do verbo aparece na gramática de Rocha Lima quando é abordada a Sintaxe. Ainda que haja um estudo anterior sobre os verbos na seção Morfologia, a relação dos verbos com os outros elementos do enunciado só aparece na abordagem da construção da oração, o que é lógico, já que a função das palavras aparece no eixo combinatório. Cabe destaque à abordagem das vozes verbais realizada pelo gramático. Ele trata do assunto como referente à atitude do sujeito, sem se referir, inicialmente, aos complementos verbais ou ao significado do verbo do enunciado. A referência ao objeto direto e sua participação na estrutura das vozes verbais só aparece no capítulo da Sintaxe. A voz é definida como "acidente que expressa a relação entre o processo verbal e o comportamento do sujeito" (ROCHA LIMA, 2011, p.170) e, apesar de inicialmente definir a voz por sua característica semântica, ao longo das classificações das vozes vemos também uma abordagem estrutural.

A transitividade verbal aparece na gramática de Moura Neves na primeira parte, ao se abordar a predicação dos enunciados. São destinadas, dentro desse capítulo, trinta e três páginas à explicação dos diferentes tipos de transitividade, relacionando o verbo ao seu complemento e 
os diversos sentidos que pode haver entre esses elementos. É uma descrição exaustiva dos fenômenos, sendo apresentados muitos tipos de predicação verbal.

Após essa breve apresentação da estrutura das gramáticas, será observado nos próximos itens como cada gramático aborda a transitividade verbal e o objeto direto.

\section{O OBJETO DIRETO EM ROCHA LIMA}

Na Gramática Normativa da Língua Portuguesa, a relação entre o verbo e seus complementos aparece na abordagem sobre predicado verbal e na abordagem sobre a transitividade verbal. O gramático define predicado verbal como aquele que "exprime um fato, um acontecimento, ou uma ação, tem por núcleo um verbo, acompanhado ou não, de outros elementos" (ROCHA LIMA, 2011, p.293) e destaca a importância em se estudar a relação entre esse verbo, núcleo do predicado, e seus complementos, porque juntos eles formam "uma expressão semântica, de tal sorte que a sua supressão [do complemento] torna o predicado incompreensível, por omisso ou incompleto" (ROCHA LIMA, 2011, p.416, grifo do autor).

A depender do tipo de complemento que recebe ou não, o verbo pode ter seis classificações diferentes: intransitivos, transitivos diretos, transitivos indiretos, transitivos relativos, 
transitivos circunstanciais e bitransitivos. Para identificar a transitividade do verbo, é necessário analisá-lo na frase.

Os verbos transitivos são aqueles que necessitam de outros termos para totalizarem a compreensão do enunciado, possuindo predicação incompleta, enquanto os verbos intransitivos são aqueles que dispensam complemento. Sozinhos eles representam a noção predicativa, isto é, possuem predicação completa. Entretanto, em alguns casos o verbo intransitivo vem acompanhado de um elemento que reforça o sentido expresso pelo verbo. A esses complementos, Rocha Lima denomina objeto direto interno e, muitas vezes, possui o mesmo radical do verbo da oração, conforme ele aponta no seguinte exemplo (ROCHA LIMA, 2011, p.306): “... morrerás morte vil da mão de um forte." "“Y-Yuca-Pirama”, Gonçalves Dias).

O objeto direto é definido por Rocha Lima como complemento verbal que "na voz ativa, representa o paciente da ação verbal" (ROCHA LIMA, 2011, p.299). Ele pode ser sujeito na voz passiva e ser substituído pelas formas pronominais átonas $\mathrm{o}, \mathrm{a}, \mathrm{os}$, as. Esse tipo de complemento verbal pode ter variados valores semânticos: indicar o ser sobre o qual cai a ação (Castigar o filho); indicar o resultado da ação (Construir uma casa); ou indicar o conteúdo da ação 
(Discutir política). Quando um verbo exige um objeto direto para complementar seu sentido, o nomeamos de verbo transitivo direto.

Em alguns casos, o objeto direto pode aparecer preposicionado, de forma facultativa, ou até de forma obrigatória. São casos de presença obrigatória da preposição os seguintes:

1) Com as formas tônicas dos pronomes pessoais:

"Júlio César conquistou

O mundo com fortaleza;

Vós a mim com gentileza." ("Redondilhas (Parte III)", CAMÕES)

"Rubião viu em duas rosas vulgares uma festa imperial, e esqueceu a sala, a mulher e a si." (Quincas Borba, CXLI, MACHADO DE ASSIS)

"Quem sabe se o destino marcara justamente a ela como a eleita?" (Negrinha, MONTEIRO LOBATO)

2) Com o pronome quem, de antecedente expresso:

"[...] perdi meu pai e senhor a quem muito amava..." (Corte na Aldeia, RODRIGUES LOBO)

"Eu sou Daniel, aquele eremita, a quem tal ano, e dia hospedaste em tua casa..."(Nova Floresta ${ }_{2}$ MANUEL BERNARDES)

3) Com o nome Deus:

"Que muito fazes em louvar a Deus, quando vives 
em prosperidade, quando em abundância, quando sem vexação nem injúria de alguém?" (MANUEL BERNARDES, 1945, I, 33C)

"Só há uma coisa necessária: possuir a Deus." (Discurso no Colégio Anchieta, 1903, RUI BARBOSA)

4) Quando se coordenam pronome átono e substantivo: “[...] o reitor o esperava e aos seus respeitáveis hóspedes..." (O monge de cister: ou, A epocha de D. João I, ALEXANDRE HERCULANO)

"Foi a comadre do Rubião, que $o$ agasalhou e mais $a o$ cachorro, vendo-os passar defronte da porta." (Quincas Borba, CXCIX,_MACHADO DE ASSIS)

5) Quando um verbo transitivo direto se usa impessoalmente, acompanhado da partícula se:

Aos pais ama-se com fervor. (ROCHA LIMA, 2011, p.301)

Há casos também em que o verbo transitivo direto se torna pronominal e acaba por exigir a presença de um complemento preposicionado (Admirar o talento de alguém / Admirar-se do talento de alguém). Esse complemento, outrora denominado objeto direto, toma a forma de um complemento relativo ${ }^{2}$. Nesses casos, o complemento relativo não deve ser confundido com um objeto direto

2 O complemento relativo é "ligado ao verbo por uma preposição determinada (a, com, de, em, etc), integra, com o valor de objeto direto, a predicação de um verbo de significação relativa" (ROCHA LIMA, 2011, p.311). 
preposicionado, pois, enquanto este deixa-se substituir por um pronome átono, aquele não permite tal substituição:

"Só há uma coisa necessária: possuir a Deus."

Só há uma coisa necessária: possuí-lo

Admirar-se do talento de alguém

Admirar-se o (?)

A definição do que é um objeto direto feita em Gramática Normativa da Língua Portuguesa é marcadamente estrutural: o objeto direto funciona como o complemento não preposicionado do verbo e deixa-se substituir por pronome átono. As suas ramificações - objeto direto preposicionado e objeto direto interno - são definidas no nível morfossintático. Esse caráter analítico reafirma a visão formalista da língua pelo gramático. Porém, verifica-se a abordagem semântica dessa função sintática ao afirmar que o objeto direto é paciente da ação verbal na voz passiva e, na voz ativa, pode se referir ao ser sobre o qual recai a ação expressa pelo verbo, o resultado dessa ação ou o conteúdo da ação.

\section{O OBJETO DIRETO EM MOURA NEVES}

A transitividade verbal aparece na Gramática de usos do português no primeiro capítulo, onde é abordado o verbo. Moura Neves faz diversas subclassificações dessa classe gramatical e uma delas é a partir de sua transitividade. A 
linguista afirma que ao se pensar na relação entre o verbo e seus complementos, "está implicada a valência verbal, isto é, a capacidade de os verbos abrirem casas para preenchimento por termos (sujeito e complemento), compondo-se a estrutura argumental." (MOURA NEVES, 2011, p.28, grifos da autora). Dessa forma, entende-se que os verbos precisam de outros elementos para que a sentença tenha sua significação completa.

Um verbo é analisado como transitivo prototípico quando pede um complemento que é paciente de mudança. Essa é uma definição que se baseia principalmente na semântica.

De acordo com Moura Neves (2011), há quatro classes principais de verbos de acordo com a transitividade: verbos cujo objeto sofre mudança no seu estado; verbos que não sofrem mudança física; verbos que possuem um complemento não preposicionado e um complemento preposicionado; e verbos que têm complementos oracionais.

O objeto direto é definido como um complemento não preposicionado. A classificação desse objeto é, então, sintática e semântica. De acordo com a transitividade do verbo, esse complemento pode desempenhar diversos papeis semânticos. A seguir estão algumas semânticas do objeto direto levantadas na gramática de acordo com a transitividade verbal (MOURA NEVES, 2011, p.28-48): 
a) Verbos cujo objeto sofre mudança no seu estado

- Quando o verbo denota criação, o objeto direto passa a existir: Minha mãe FEZ-me um bolo. (MOURA NEVES, 2011, p.28 -grifos da autora);

- Quando o verbo denota destruição, o objeto deixa de existir: Encarregamos uma firma de DEMOLIR a casa velha. (MOURA NEVES, 2011, p.28, grifos da autora);

- Quando o verbo denota mudança de espaço, o objeto altera sua localização: MUDOU uma caixa da mesa de cabeceira para a prateleira. (MOURA NEVES, 2011, p.28, grifos da autora).

b) Verbos que não sofrem mudança física: nesse caso, os objetos podem ser preposicionados ou não. Quando não preposicionado, isto é, quando objeto direto, a linguista não aponta diferença semântica neles.

c) Verbos que possuem um complemento não preposicionado e um complemento preposicionado.

- Quando o verbo traz noção de lugar, o objeto direto muda espacialmente: $A$ irmã COLOCOU o roupão no cabide. (MOURA NEVES, 2011, p.30, grifos da autora); - Quando o verbo denota doação, o objeto direto muda de beneficiário: DEU ao genro um engenho com setenta escravos. (MOURA NEVES, 2011, p.31, grifos da autora). 
d) Verbos que têm complementos oracionais

- Quando o verbo implica um fato verdadeiro, o objeto direto indica o fato constatado pelo enunciador: $E u$, por mim, apenas SEI que Carlos veio me trazer em casa. (MOURA NEVES, 2011, p.32, grifos da autora);

- Quando o verbo é dicendi, o objeto direto é o conteúdo do que se é dito: $O$ gordinho GRITAVA que aquilo era um desaforo. (MOURA NEVES, 2011, p.48, grifos da autora).

A classificação dos verbos quanto à transitividade $\mathrm{e}$ à distribuição dos papeis semânticos do objeto direto foram realizadas pela linguista após a análise de dados de 70 milhões de ocorrências da língua armazenadas no Centro de Estudos Lexicográficos da UNESP. Assim, não se verifica uma normatização da sintaxe, mas uma análise descritiva dos fenômenos da língua que ocorrem no seu uso espontâneo. Porém, apesar de não se apegar a uma análise puramente estrutural, a gramática exige que o seu leitor tenha conhecimento prévio da abordagem tradicional da língua, pois não se define de forma sistemática o que é um objeto - o foco são as produções de sentido que ocorrem na relação entre verbo e complemento. Estabelecendo como prioridade o sentido produzido dentro de diversas situações de troca comunicativa, a linguista insere a gramática na linha funcionalista de análise linguística. 


\section{CONSIDERAÇÕES FINAIS}

Vê-se que a explicação de Rocha Lima acerca da transitividade verbal e do complemento direto baseia-se em exemplos retirados de obras literárias da língua portuguesa, e não do uso cotidiano dos falantes do português no Brasil. Assim, as regras de funcionamento da norma culta da língua são privilegiadas sobre as demais normas, conforme já denunciado pelo gramático no prefácio da gramática. Ao demarcar essa variedade da língua - não espontânea e literária - como a norma a ser ensinada na escola, o gramático afasta o tido como "correto" da variedade levada pelos alunos à escola, mas permite que os discentes alcancem e conheçam outras estruturas da língua.

Diferentemente ocorre na gramática de Moura Neves, onde não se vê a primazia de uma norma linguística sobre as demais. Descrever somente a norma culta não é o objetivo da linguista, como já denuncia o título da gramática - o objetivo é sistematizar todas as formas de se falar o português no Brasil. Um professor que busque trazer a perspectiva funcionalista para as salas de aula deve, portanto, ensinar mecanismos de análise e compreensão das diversas normas da língua, incluindo a norma coloquial utilizada pelo aluno. Cabe destacar que ao descrever o Português brasileiro, 
todas as normas receberão destaque, inclusive a norma culta: não é a exclusão da norma culta das salas de aula que deve ocorrer, e sim a inclusão da análise das outras variações da língua.

Quando um professor explica a transitividade verbal e o objeto direto com foco na morfossintaxe, assim como Rocha Lima, faz com que o aluno relacione as diferentes partes da sentença de forma classificatória e exploratória, como ocorre em outras ciências (Biologia e Matemática, por exemplo). Desenvolver essa habilidade dos alunos é o primeiro passo para que eles acessem, a partir da estrutura, os sentidos implicados ao fazer uso do objeto direto explícito ou oculto na oração, por exemplo, ou que compreendam o sentido implicado da colocação do objeto direto como tema do enunciado.

Sendo assim, o objetivo das aulas de gramática deveria ser levar os alunos a reconhecerem as funções sintáticas, conseguirem relacioná-las em uma oração e, com essa atividade formal da língua, desvendar as implicações semânticas que ocorrem nas relações entre as partes da estrutura da oração. É preciso levar ao aluno a reflexão de que, por exemplo, um objeto direto funciona semanticamente como paciente de mudança e que por isso na oração $A$ 
menina come a uva, o sintagma a menina não funciona como objeto, mesmo sendo passível de substituição por um pronome átono em uma reestruturação do enunciado: $A$ uva come-a. Da mesma forma, sabe-se que a uva é objeto direto porque, além de corresponder a um complemento verbal, não possui preposição e pode ser trocada por um pronome átono, definição estrutural. Observa-se, então, a necessidade de correlacionar as duas formas de análise linguística nas escolas: o formalismo e o funcionalismo.

\section{REFERÊNCIAS}

BECHARA, Evanildo (2007). O ensino da gramática. Opressão? Liberdade? 11.ed. São Paulo: Ática.

CASTILHO, Ataliba (2002). "Lingüística cognitiva e tradição funcionalista". Seminário do Grupo de Estudos Lingüísticos do Estado de São Paulo. São Paulo: FFLCH / USP, 23-25 de maio.

CHIAVEGATTO, Valeria (2009). "Introdução à Linguística Cognitiva". Matraga, Rio de Janeiro, 16(24), janeiro/junho.

CORTEZ, Cinara (2011). "Formalismo x funcionalismo: abordagens excludentes?". PERcursos linguísticos; Vitória, 1(1).

FUZER, Cristiane; CABRAL, Sara (2014). Introdução à gramática sistêmicofuncional em Língua Portuguesa. São Paulo: Mercado de Letras.

GÖRSKI, Edair; COELHO, Izete; MAY Guilherme (2010). Sociolinguística. Florianópolis: UFSC.

GUMPERZ, John (1982). Discourse Strategies. Cambridge: Cambridge University Press.

HALLIDAY, Michael (2002). An introduction to functional grammar. 2.ed. London: Edward Arnold.

MOURA NEVES, Maria Helena (2011). Gramática de usos do português. 2.ed. São Paulo: Editora UNESP 
NASCIMENTO, Felipe Augusto; NASCIMENTO, Vinícius (2011). "Bloomfield revisitado: processos de formação de palavras do vocabulário chayenês". Analecta, Guarapuava, 12(1), jan./jun.

PERINI, Mário (2010). Gramática do português brasileiro. São Paulo: Parábola.

ROCHA LIMA, Carlos Henrique da (2011). Gramática normativa da língua portuguesa. 49.ed. Rio de Janeiro: José Olympio.

VITRAL, Lorenzo (1996). O que é gramática gerativa?. In www.periodicos. letras.ufmg.br/index.php/anais_lingua_portuguesa/article/.../6961 Acesso em 15.jun.2019.

Bárbara de Brito Cazumbá é Mestra em Língua Portuguesa pela UERJ. Atua como professora de Ensino Fundamental do 2 o segmento nos municípios de Duque de Caxias e Niterói. Desenvolve pesquisa na área de descrição da língua, com foco em discurso, ethos e construção de identidade através de aspectos semiolinguísticos.

Lattes: http://lattes.cnpq.br/9581859442474831.

E-mail: barbricaz@yahoo.com.br 